\title{
Phytopathology
}

\section{A Review of Current Knowledge of Resistance Aspects for the Next-Generation Succinate Dehydrogenase Inhibitor Fungicides}

\author{
Helge Sierotzki and Gabriel Scalliet
}

Syngenta Crop Protection, Research Biology, Schaffhauserstrasse, Stein, Switzerland. Accepted for publication 11 April 2013.

\begin{abstract}
Sierotzki, H., and Scalliet, G. 2013. A review of current knowledge of resistance aspects for the next-generation succinate dehydrogenase inhibitor fungicides. Phytopathology 103:880-887.

The new broad-spectrum fungicides from the succinate dehydrogenase inhibitor (SDHI) class have been quickly adopted by the market, which may lead to a high selection pressure on various pathogens. Cases of resistance have been observed in 14 fungal pathogens to date and are caused by different mutations in genes encoding the molecular target of SDHIs, which is the mitochondrial succinate dehydrogenase (SDH) enzyme. All of the 17 marketed SDHI fungicides bind to the same ubiquinone binding site of the SDH enzyme. Their primary biochemical mode of action is the blockage of the TCA cycle at the level of succinate to fumarate oxidation, leading to an inhibition of respiration. Homology models and docking simulations explain binding behaviors and some peculiarities of the cross-resistance profiles displayed by different members of this class of fungicides. Furthermore, cross-resistance patterns among SDHIs is complex because many mutations confer full cross resistance while others do not. The nature of the mutations found in pathogen populations varies with species and the selection compound used but cross resistance between all SDHIs has to be assumed at the population level. In most of the cases where resistance has been reported, the frequency is still too low to impact field performance. However, the Fungicide Resistance Action Committee has developed resistance management recommendations for pathogens of different crops in order to reduce the risk for resistance development to this class of fungicides. These recommendations include preventative usage, mixture with partner fungicides active against the current pathogen population, alternation in the mode of action of products used in a spray program, and limitations in the total number of applications per season or per crop.
\end{abstract}

Among the 55 classes of fungicides listed by the Fungicide Resistance Action Committee (FRAC), the sterol biosynthesis inhibitors and quinone-outside inhibitors (QoIs) are two of the most relevant for disease control in commercial agriculture. However, the succinate dehydrogenase inhibitor (SDHI) class is the fastest growing in terms of new compounds produced and launched into the market. The market adaptation to the new technology and its penetration seems to be very fast. In spring 2012, almost $60 \%$ of the cereal farmers in the United Kingdom indicated use of at least one SDHI-containing product per season (3), and this occurred only two seasons after first introduction. In Germany, SDHI treatments in cereals grew from $\approx 15$ to $25 \%$ of the market in 2012 (32). The reason for the rapid adoption of SDHIs is their high level of activity and the lack of effective alternative control options. Many cereal pathogens have developed resistance to the QoIs (17), and reduced sensitivity to the demethylation inhibitor (DMI) fungicides (17), which generates

Corresponding author: H. Sierotzki; E-mail address: helge.sierotzki@ syngenta.com

http://dx.doi.org/10.1094/PHYTO-01-13-0009-RVW

(c) 2013 The American Phytopathological Society increased challenges for the farmers to efficiently control diseases and maintain or increase crop yield and quality.

The class of compounds inhibiting complex II of fungal respiration was originally called carboxamide fungicides, with the earliest compound in this class, carboxin, being first marketed in 1966 (61). This narrow-spectrum fungicide was used mainly as a seed treatment to control basidiomycete pathogens such as smuts. Thereafter, benodanil, fenfuram, mepronil, flutolanil, furametpyr, and thifluzamide followed between 1971 and 1997; however, these compounds gave only slightly broader-spectrum control compared with carboxin. The first carboxamide with truly broad-spectrum foliar activity was boscalid, launched in 2003 (20,44,52).

In recent years, several new fungicides inhibiting the succinate dehydrogenase (SDH) enzyme have been launched or announced and collectively termed SDHIs. FRAC (17) is currently listing 17 SDHI compounds (benodanil, benzovindiflupyr, bixafen, boscalid, carboxin, fenfuram, fluopyram, flutolanil, fluxapyroxad, furametpyr, isopyrazam, mepronil, oxycarboxin, penflufen, penthiopyrad, sedaxane, and thifluzamide), belonging to different chemical types. Currently the "overall" spectrum of SDHI fungicides is extremely broad, being comparable with the QoI spectrum, with the exception of oomycete activity, which is still lacking. 
By delivering a broader spectrum of activity with the more recent SDHI fungicides compared with earlier ones (2), several pathogens with intrinsically high risk for developing resistance have now come into focus, such as Alternaria alternata, Botrytis cinerea, Podosphaera xanthii, Mycosphaerella fijiensis, and M. graminicola. Most of these pathogens have already developed almost complete resistance or reduced sensitivity to the major fungicide classes used to control them (resistance to methyl benzimidazole carbamates or QoI, or sensitivity shift to DMI). The discovery, development, and registration of new fungicides with novel modes of action is time and resource consuming; therefore, it is important that the use recommendations for SDHIs have the clear goal to delay resistance development as long as possible. In many plant pathogens, resistance development can affect the performance of highly active single-site fungicides. In this light, the SDHI fungicides are a fundamental cornerstone for resistance management but, in the meantime, this class itself is also threatened by resistance. Therefore, it is important to use all available knowledge to protect their longevity. In the current review, we present information on binding, biochemistry, resistance, selection, cross resistance, and resistance-management strategies for SDHI fungicides.

Chemical scope. SDHIs are structurally very diverse but they display an essential common feature, which is the amide bond.
The "core" or "head" of the molecule, which is attached to the carbonyl of the amide bond, is used for classification $(44,63)$, with six main chemical types being distinguished (Fig. 1, reddashed left panel). The classification is based on the nature of the substituted five- or six-membered ring systems. The most represented type in terms of marketed molecules is the pyrazole carboxamides, followed by the benzamides and oxathiin carboxamides. The core moiety is essential for binding and in vivo potency, and this part of the molecule enters deeply into the active site of SDH. On the amine side of the amide bond, the moiety can be split into two main components. First is the linker, which may or may not carry substituents (Fig. 1, blue-dashed upper right panel). The most frequent linker is a phenyl group, which is normally substituted in the ortho position by a hydrophobic rest. The angle defined by the amide and the ortho substituent in the phenyl ring is important for activity. A close angle is maintained, with the thiophene ring system replacing the phenyl; and, in the case of an ethyl linker, a gauche conformation may help in maintaining a similar angle value. The hydrophobic rest is the second main component; it is likely to be partly exposed at the surface of the enzyme but still has a very important influence on the biological spectrum and potency of the compound (Fig. 1, green-dashed bottom right panel).

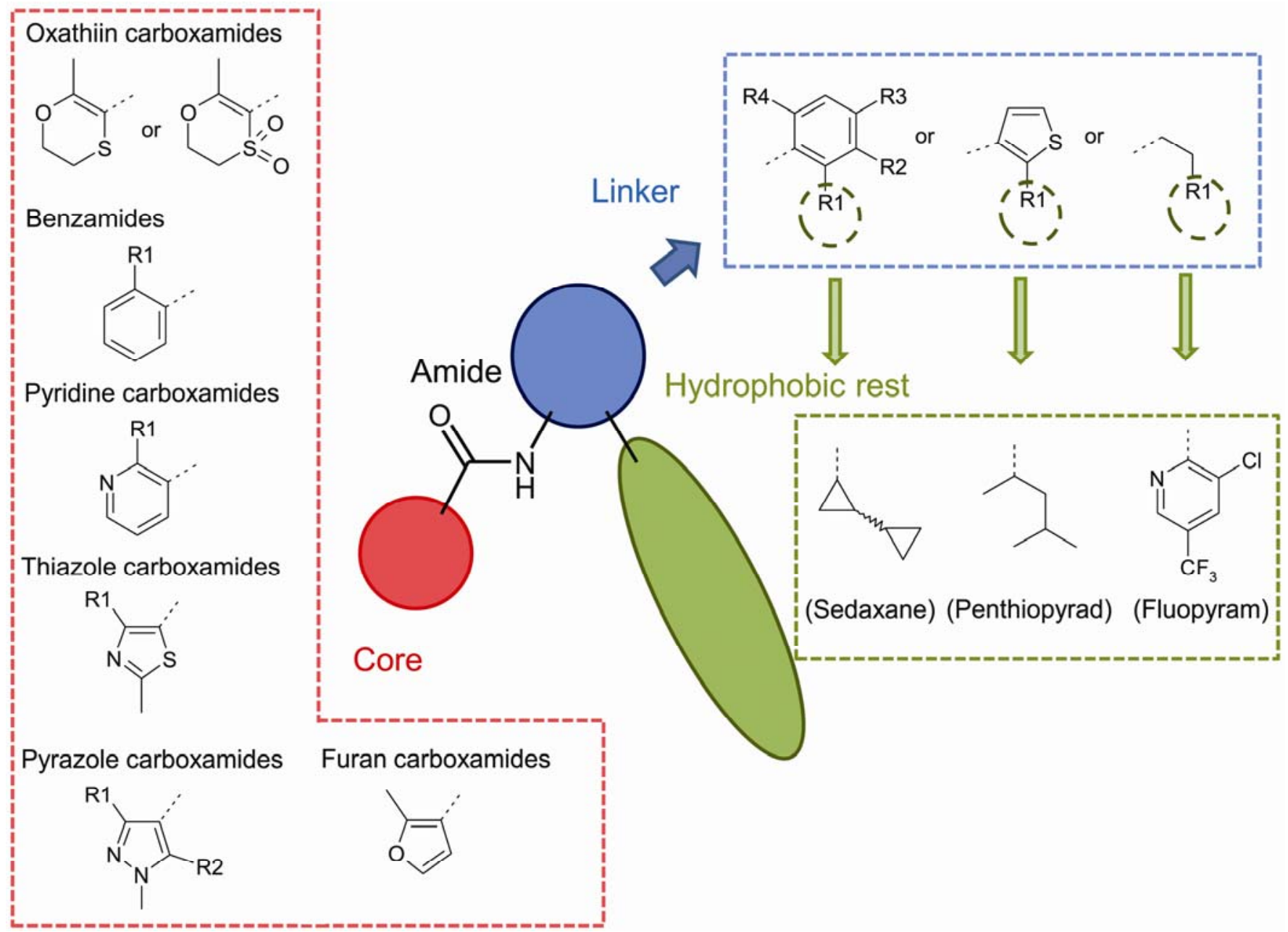

\section{FIGURE 1}

Schematic overview of chemical structures of succinate dehydrogenase inhibitors (SDHIs). The amide bond is strictly conserved across all SDHIs and defines the orientation of the molecule. The "core" moiety is attached to the carbonyl of the amide bond. Six core ring systems can be found which define the current chemical classification for SDHIs. On the amine side of the amide bond, a "linker" is attached. The linker varies but is usually a phenyl group; it may be a simple nonsubstituted phenyl ring (carboxin) or carry substituents at different positions. The ortho position usually carries a larger "hydrophobic rest" which is the last component of the molecule. 
Biochemical aspects, binding. The SDH enzyme (also termed succinate ubiquinone oxidoreductase [EC 1.3.5.1]) is a mitochondrial heterotetramer composed of four nuclear-encoded subunits (13). The SDHA and SDHB subunits are exposed to the matrix of the mitochondria and SDHC and SDHD are integral membrane proteins anchoring the SDHAB dimer to the internal membrane of the mitochondria. In contrast to other dehydrogenases of the TCA cycle, the SDH enzyme transfers succinate-derived electrons directly to the ubiquinone pool of the respiratory chain and not to soluble NAD+ intermediates. For this reason, SDH is considered to be an essential component of the respiratory chain and is also termed complex II. SDH inhibitors can be classified into two main categories: those binding to the succinate-binding pocket (e.g., malonate) and those binding to the ubiquinone-binding pocket (e.g., carboxamides). All crop protection SDHIs target the ubiquinone-binding pocket, structurally defined by the interface between the SDHB, -C, and -D subunits. Although a few amino acid residues important in the catalysis of ubiquinone reduction are strictly conserved across species, most SDHC and SDHD residues display a high degree of variation across species (13). This feature is largely responsible for the diversity in chemical structures and diversity of biological spectrum displayed across SDHIs.

SDHIs bind strongly to the ubiquinone-binding (Qp) site; upon binding, they physically block access to the substrate which consequently prevents further cycling of succinate oxidation. $\mathrm{SDH}$ tridimensional structures have been determined by X-ray crystallography for three species: Escherichia coli (66); pig, Sus scrofa (55); and chicken, Gallus gallus (26). Multiple SDHinhibitor co-crystals could be obtained and structures resolved for a number of Qp site inhibitors, including carboxamides $(26,45)$. Despite a low primary sequence conservation for the of SDHC and SDHD proteins across species, homology models have been reported for $M$. graminicola and B. cinerea and SDHI docking predictions performed $(16,21,46)$.

The main features in the binding interaction are depicted in Figure 2, which describes the main Qp site residues (M. graminicola numbering) predicted to be in direct interaction with the inhibitor. The central amide bond establishes H-bonds with Trp224 in SDHB, Tyr130 in SDHD, and through a water molecule to Ser83 in SDHC; these residues are strictly conserved across species because they are directly involved in ubiquinone binding and catalysis $(50,58,70)$. The core is deeply buried within the binding pocket (Arg87 in SDHC and His267 in SDHB) located at the bottom of the cavity and may display $\pi$-clouds interaction with this moiety of the inhibitor. An H-bond possibly occurs between the nitrogen of the histidine and a heteroatom of the core cycle carried by many SDHIs. The "linker" mainly interacts through hydrophobic interaction with some SDHB and SDHC residues, including Pro220 in SDHB, which is also strictly conserved. The "hydrophobic rest" is mainly interacting by hydrophobic interactions with residues of SDHC and SDHD subunits, which form a groove on the surface of the protein exposed to the lipids of the internal mitochondrial membrane.

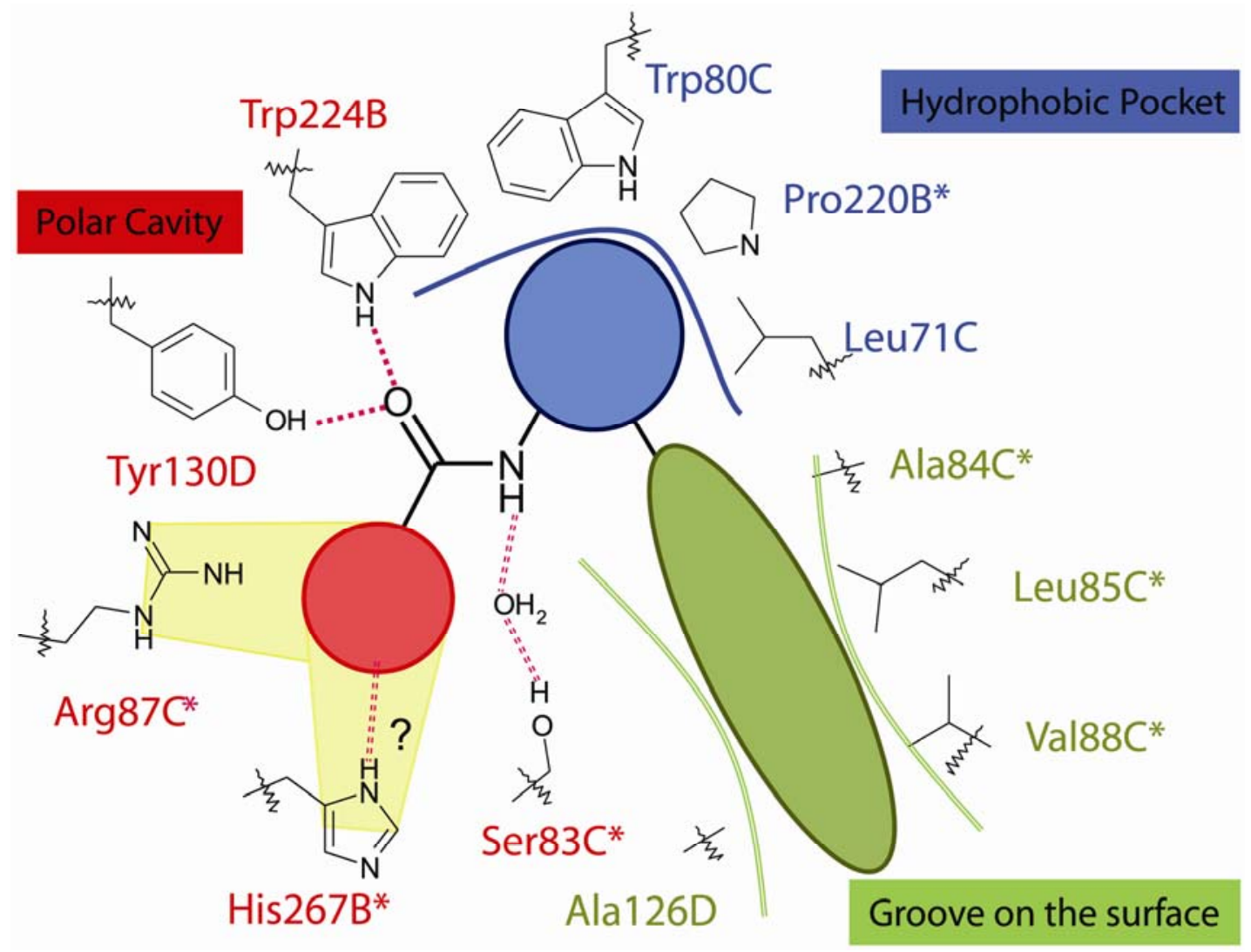

FIGURE 2

Schematic view of binding mode, intermolecular interactions, and toxophore of carboxamides inside Mycosphaerella graminicola ubiquinonebinding site. In red is the polar cavity interacting with the acid core ring (aromatic, heteroaromatic, or aliphatic) and amide; in blue is the hydrophobic pocket interacting with the linker (aromatic or aliphatic); in green is the groove on the protein surface accommodating the putative hydrophobic rest of succinate dehydrogenase inhibitors (SDHIs). Dashed lines depict hydrogen-bonds or electrostatic interactions, full lines represent hydrophobic or steric contacts, and yellow boxes are putative interactions with $\pi$-clouds. Double-lines are interactions not mandatory for molecular recognition. Residues found to confer SDHI resistance upon substitution are indicated by asterisks. 
Two residues of the Qp site (Trp224 and Tyr130 in SDHB and SDHD, respectively) which are key for SDHI binding have not yet been found mutated in either SDHI resistance mutagenesis screens or field isolates. This suggests that their substitution to other residues may not confer any selective advantage in the balance between impaired inhibitor binding and maintained ubiquinone binding and reduction. Among the most frequently mutated position in field isolates is the histidine at the bottom of the cavity (His267B), which has been found substituted for other residues in all fungal species where SDHI-resistant isolates have been reported (Table 1). The proline residue at position 225 in SDHB (position 220 in $M$. graminicola) interacting with the linker is also frequently mutated in $B$. cinerea $(53,62)$. Apart from these important residues of the Qp site, a range of other substituted positions can lead to resistance by having an impact on the shape of the binding pocket through possible longer-range domino effects. A heme is located at the interface between SDHC and -D subunits and the heme's propionates form part of the Qp site. Residues in the close vicinity of the heme propionates and more distant SDHC and SDHD histidine residues involved in heme's iron chelation can also confer resistance upon substitution. Such positions seem particularly relevant for conferring resistance in Alternaria spp. (SDHC H134 and SDHD H133) (Table1).

Substitutions conferring SDHI resistance display a negative effect on enzyme efficiency; some mutations can decrease SDH activity by $>90 \%$. This factor is likely to have a negative influence on the fitness of resistant isolates although, to date, no clear evidence exists proving this to be the case $(16,31,46)$.

Spectrum of activity. The most recent SDHI fungicides possess a high level of activity against many of the most important pathogens causing diseases in crops. Compounds such as isopyrazam (24), bixafen (11,56), penthiopyrad (65), and fluxapyroxad (47) are or will be used to control pathogens of cereals, but they also display high activity against pathogens of fruit trees,

\begin{tabular}{|c|c|c|c|c|}
\hline \multicolumn{5}{|c|}{$\begin{array}{l}\text { TABLE } 1 \\
\text { List of pathogens with reported resistance to succinate dehydrogenase inhibitor (SDHI) fungicides, } \\
\text { their estimated resistance status, and mutations described conferring the resistant phenotype }\end{array}$} \\
\hline Species & Host & Resistance to SDHI ${ }^{\mathrm{a}}$ & Mutations in sdh genes & References \\
\hline \multirow[t]{2}{*}{ Alternaria alternata } & Almond & ++ & sdh b: H277Y/R/L & $4,49,53$ \\
\hline & Potato & & sdh c: H134R, S135R & \\
\hline \multirow{2}{*}{ A. solani } & Potato & & sdh c: H134R & \\
\hline & & & sdh d : T28A, A47T, D123E, H133R & \\
\hline \multirow[t]{2}{*}{ Botrytis cinerea } & Grape & $+:++; \checkmark$ & sdh b: P225L/F/T,N230I, H272Y/R & $1,52,53,62$ \\
\hline & Strawberry & & sdh b: H278Y/R & \\
\hline Corynespora cassicola & & & sdh d: S89P & \\
\hline Sclerotinia sclerotiorum & Oil seed rape & + & sdh d: H132R & 21,53 \\
\hline Didymella bryoniae & Cucumber & ++ & sdh b: H277Y & 54 \\
\hline Ustilago maydis & Corn? & $-? ; \checkmark$ & sdh b: H257L & 29 \\
\hline U. nuda & Barley & $+?$ & $?$ & 37,41 \\
\hline Botrytis elliptica & Tulip bulbs & ++ & sdh b: H272Y/R & 17 \\
\hline \multirow[t]{2}{*}{ Aspergillus oryzae } & & $?$ & sdh b: H249Y/L/N, & 48 \\
\hline & & & sdh c: T90I & \\
\hline \multirow[t]{3}{*}{ Lab mutants (in common) } & & & sdh b: R265P, H267L, H267N, H267Y & \\
\hline & & & sdh c: L85P, N86K, & \\
\hline & & & sdh d: D129E, D129T & \\
\hline Pyrenophora teres & Barley & + & sdh b H277Y & 17 \\
\hline
\end{tabular}


vegetables, and field crops. However, other SDHIs are differentiated by higher activity toward fungal pathogens of broadleaved rather than graminaceous hosts (i.e., boscalid and fluopyram) (33). The physic-chemical properties and spectrum of activity of sedaxane (68), penflufen (30), fluxapyroxad (25), and fluopyram (40) are well suited for seed treatment usage. The spectrum of pathogens controlled by the SDHIs is very broad, which is reflected by the number of pathogens already monitored and reported in FRAC (17): 8 plant pathogens for monocotyledonous and 11 for dicotyledonous crop plants. The broad and overlapping spectrum of the modern SDHI compounds may lead to an intensive application regime in some important areas (e.g., cereals in northwestern Europe, where the coverage area might reach $40 \%$ or more of the total cultivated area) (Syngenta internal estimation [32]). This intensity of usage will lead to a high selection pressure on the pathogen populations, because the majority of these populations will receive one or several applications of SDHI-containing fungicides during the same cropping season. Given the extent of crop coverage with SDHIs, the selection pressure they exert on the pathogen population remains very high even when mixtures with compounds from other fungicide classes are used.

Mechanisms of resistance. First indications of possible mutations mediating resistance to carboxin were already reported for Ustilago maydis and Aspergillus nidulans in the 1970s $(18,19,59)$. These mutants were selected after UV irradiation on fungicideamended media. The studies showed that mutations in succinate dehydrogenase genes are responsible for resistance. Interestingly, resistance factors (ranging between 20- and 100-fold) were different between different allelic mutants of the same gene. A later study by White and Thorn in U. maydis (64) showed that the efficacy of analogs of thiophene carboxamides was differentially affected by resistant mutants and suggested that carboxin-selected resistant mutants might be controlled by structurally different SDHI compounds. A similar observation of differentially resistant $U$. nuda strains has been reported by Grouet et al. (22) for the comparison of carboxin and fenfuram to flutolanil and mepronil. Leroux and Berthier (34) reported on resistance of Puccinia horiana toward carboxin but the resistance factors were rather low $(\approx 10$-fold) and the resistance seemed to fade upon cultivation of the strain. Resistance to carboxin was described as monogenic in $U$. nuda on barley in field populations in France and Canada but the molecular mechanism of resistance was not elucidated (42). Artificial mutants with amino acid substitutions in SDHB were selected in vitro in $U$. maydis $(\mathrm{H} 257 \mathrm{~L})$ and in M. graminicola $(\mathrm{H} 267 \mathrm{Y})$ expressing resistance to SDHIs such as carboxin, flutolanil, and boscalid $(12,29,51)$. Also, in subunit $\mathrm{C}$ of SDH, a mutation, N80K, was detected in Coprinus cinereus and A. nidulans (28).

Recently, after the increased usage of SDHIs as foliar fungicides, resistance to them has been reported in B. cinerea $(36,53$, 62), Alternaria alternata (4,7), Didymella brioniae (54), Corynespora cassiicola (38), and Podosphaera xanthii (39). In these cases, mutations in the $s d h$ genes have been found to be the reason for the resistant phenotype. The most frequent mutation is a Qp site SDHB histidine $(\mathrm{H})$ replaced with a tyrosine $(\mathrm{Y})$ but other amino acids substitutions were also found, such as leucine (L) or arginine (R) (Table 1). Mutations in other subunits can also be detected, such as $s d h \mathrm{C}$ and $s d h \mathrm{D}$. In most pathogens, more than one mutation seem to be selected under field conditions but they rarely occur together. In total, $>27$ mutations conferring resistance to SDHIs have been reported to date in field populations of different pathogens (Table 1). Thus far, no mechanism apart from mutations in $s d h$ genes has been reported to be responsible for resistance in field strains.

Cross resistance. The resistance factors conferred by target site mutations detected in either field isolates or artificial mutants differ depending on the SDHI compound or mutation pair and the pathogen species $(27,46)$. Some contrasting cross-resistance behaviors can be explained by the different binding modes of the SDHI molecules into the three-dimensional model of the binding pocket (see above and compare Figures 1 and 2) (46). Phenotypically, it is observed that certain compounds display negative cross resistance on particular mutations such as SDHB H277Y in A. alternata (49). In C. cassicola, a leaf spot disease on cucumber in Japan, and P. xanthii, powdery mildew in cucurbits, a similar effect of the histidine to tyrosine change at the homolog position in SDHB is described (27). This phenomenon is observed when boscalid, bixafen, isopyrazam, and similar compounds are compared with fluopyram. A similar study has been published with D. bryoniae (8). However, many other mutations can affect all SDHIs similarly, as shown in A. alternata for the SDHC H134R mutation (49). A subsequent publication confirmed that SDHC H134R mediates resistance toward boscalid and fluopyram and, again, suggests that boscalid can "pre-select" populations (9). More recently, a study in $A$. solani demonstrated again that resistance to boscalid does not imply resistance to fluopyram in some boscalid-selected field isolates, although several mutations in this pathogen have also been detected which do seem to confer cross resistance (Table 1) (15). Last year, a study with $B$. cinerea isolated from strawberry indicated differential behavior of five different mutations at three different codons of $s d h \mathrm{~B}(\mathrm{P} 225 \mathrm{~F}$, $\mathrm{N} 230 \mathrm{I}$, and $\mathrm{H} 272 \mathrm{~L} / \mathrm{R} / \mathrm{Y}$ ) to boscalid, fluopyram, isopyrazam, bixafen, fluxapyroxad, fenfuram, benodanil, and carboxin (60). The mutation leading to the amino acid change P225F in the SDHB conferred resistance to all SDHI fungicides. Other mutations revealed either lower resistance factors (such as SDHB H272L) or even a different sensitivity pattern (such as SDHB $\mathrm{H} 272 \mathrm{Y}$ or $-\mathrm{R}$ ). Even mutations at the same amino acid position can confer a completely different sensitivity pattern toward the SDHI fungicides. For example, the change from H272 to Y272 in SDHB mediates decreased sensitivity toward boscalid, isopyrazam, and bixafen yet hypersensitivity to fluopyram. When this same position is substituted by a leucine (SDHB H267L) in SDHB in $M$. graminicola lab mutants, a pattern of complete cross resistance toward all SDHI fungicides, including fluopyram, is observed (46). These examples show that it is crucial to determine the genetic background in order to evaluate the cross-resistance behaviors of the SDHIs. It seems that there are species-specific preferences for some of the mutations but, even more frequently, mutations display different resistance patterns depending on the species they occur in. In addition, relevant variation in sensitivity can be observed across isolates of the same species carrying the same mutation in the SDH enzyme. This was reported for boscalid in B. cinerea strains isolated from apple in 2009 in the United States (67). It indicates that other factors besides target sequence are involved in the sensitivity to SDHIs (46). However, despite all the differences and specific interactions described, it must be assumed that the SDHI fungicides are cross resistant at least at the population level. This means that a particular pathogen can develop the optimal mutation or mix of mutations (in either individuals or populations), leading to reduced sensitivity or even resistance.

Based on resistance factor determinations, only some of the mutations found in studies using artificially generated mutants $(16,46)$ appear to induce such strong resistance factors that field performance is affected (e.g., SDHB H267L or SDHC N86K in M. graminicola). Similarly, among the mutants found in field populations, only certain mutations (such as SDHB H267L or SDHC H145R, homolog to SDHC H134R in A. alternata, or P225L in B. cinerea for at least certain SDHI fungicides) (57) are suspected to reduce the efficacy of the newest generation of SDHI fungicides to the same extent as G143A has for QoIs. The moderate decrease in sensitivity to SDHIs observed with other 
mutations should lead to more of a shift to decreased sensitivity, similar to F129L for the QoIs or mutations in the cyp51 genes for the DMIs.

Sensitivity or resistance situation in different pathogens. After the introduction of the carboxamide fungicides to control basidiomycete pathogens such as $U$. nuda or Rhizoctonia solani, sporadic reports of resistance in $U$. nuda field isolates were published $(37,41)$. However, overall resistance did not evolve significantly during this early time of SDHI usage, when this class of fungicide was mainly used as a seed treatment.

The current resistance situation is annually reported by the relevant FRAC working groups (17). The most important pathogens for which SDHI resistance has been detected in field isolates are medium- to high-risk pathogens: $B$. cinerea, A. alternata, D. bryoniae, C. cassiicola, and P. xanthii (Table 1). However, in none of the above-mentioned cases has the spread of resistance been as dramatic as it was for QoI fungicides after resistance emerged. In other pathogens, the first single cases of resistance have been reported such as Sclerotinia sclerotiorum and A. solani. Because the most recently developed members of the SDHI class of chemistry are currently being introduced to the market, it is assumed that their usage will increase the selection pressure on plant pathogen populations. In crop species such as grape, nut trees, cucumber, or oil seed rape where SDHI-containing fungicides have been used for several years, resistance has been detected in high-risk pathogens (Table 1). However, in these pathogens (B. cinerea on grape or $S$. sclerotiorum on oil seed rape), the frequency of resistance, in most cases, is not high enough to affect field performance, especially when a proper mixture partner is used, which is itself active against the current population in the field. However, if mitigation strategies are applied too late or not followed appropriately, resistance may increase and would probably lead to a visible reduction in field efficacy. This includes $A$. alternata on nut trees in the United States (5), D. bryoniae on cucumber in the United States, and $C$. cassiicola on cucurbits in Japan, but also B. cinerea on apple, strawberry, kiwi, and grape $(6,10,35)$. In some of these cases, the resistance induced by the mutations present was strong enough to affect field performance.

Recent findings with single isolates of $M$. graminicola and Pyrenophora teres carrying mutations in $s d h$ genes leading to reduced sensitivity to SDHI fungicides were reported at the SDHIs working group of the FRAC (17). In M. graminicola, the alteration $\mathrm{T}$ to $\mathrm{N}$ in the SDHC at position 79 was detected in one isolate. The resistance factor is described as low, putatively not affecting the performance of SDHI fungicides. This particular mutation has not been described before, even through artificial mutagenesis. A similar alteration from $\mathrm{T}$ to $\mathrm{I}$ at the same position led to a resistance factor of $\approx 20$ for isopyrazam and boscalid. The mutation found in $P$. teres in the SDHB gene at position 277 leading to an $\mathrm{H}$ to $\mathrm{Y}$ change is well known from other pathogens and has similar characteristics in net blotch as described above for other species.

The emergence of resistance to fungicides has been shown to be occurring independently in different geographical areas, with the example of the QoI resistance in M. graminicola and Plasmopara viticola $(14,57)$. This also has been shown in the study by Yin et al. (67) for the SDHI resistance of $B$. cinerea from apple. However, the association of resistance evolution to specific genetic groups needs to be further exemplified and tested in the future.

It should be noted that there are many pathogens in important crops which remain fully sensitive to the SDHI fungicides (at the current detection level, using bioassays); this includes pathogens of cereals, black sigatoka on banana, apple scab, and many more. For some of these pathogens, the current sensitivity status can be followed on the FRAC internet page (17) (e.g., M. fijiensis, Rhyn- chosporium secalis, Venturia inaequalis, Phakospora pachyrhizi, and Ramularia collo-cygni).

Conclusions and recommendations. In the FRAC (17), SDHI resistance management guidelines have been established for several host-pathogen systems. These guidelines are based on restriction of applications and mixtures of SDHIs with other noncross-resistant fungicides with similar activity. However, some of the currently available products are mixtures of SDHIs with QoIs. Unfortunately these products have been used in pathogen-host combinations where QoI resistance was already relatively frequent; therefore, in many instances, the SDHI fungicide was the major disease-controlling component and considerable SDHI selection pressure would have been exerted on the pathogen populations. These examples show that design and use recommendations need to be made in relation to current sensitivity status in field populations targeted by the fungicide products. The interesting feature of resistance toward SDHI fungicides is that, often, more than one or two mutations can be detected in the affected populations. In A. alternata isolates from almond tested with different fungicides (two different SDHIs solo and one in mixture), different frequencies of eight mutations or combinations of mutations were detected (49). These mutations can have a slightly different effect on the sensitivity to particular SDHI fungicides. Therefore, it is assumed that one SDHI prepares the populations more or less for any other SDHI (preselection) and any activity advantages, based on partial cross resistance, may be only transient (49).

The introduction of the SDHIs as a novel fungicide class to control many of the most important plant pathogens was timely. QoI resistance is either well established or further progressing among plant pathogen populations; for example, several cereal pathogens or recently detected resistance in Cercospora sojina on soybean (23) and Rhizoctonia solani on rice (43). The adaptation to DMIs is continuing; for example, cereal pathogens such as $M$. graminicola on wheat (17) and P. pachyrhizi on soybean (Syngenta internal [17]). The novel, highly active compounds of the SDHI class will be quickly adopted by the markets, as described above. Major product concepts presented to date are based on mixtures of SDHIs with DMIs but other mixture strategies are also available, such as SDHI mixed with anilinopyrimidine fungicides $(24,47,56)$. Even mixtures with QoI are continuing to be progressed but should be applied only in special cases (for control of QoI low-risk pathogens) or in conjunction with a monitoring program. However, the broad acceptance, widespread usage, and high activity of SDHIs also might be an obstacle to their sustainability, because the risk of resistance development is elevated and needs to be addressed by appropriate mitigation. In some pathogen-crop systems, resistance has been found after only a few years of usage of either the solo SDHI fungicides or in mixtures with QoI fungicides (Table 1).

An important aspect in the development of resistance toward SDHI is the possible fitness cost of target mutations in particular pathogens. The fact that target resistance to SDHI can be found in field strains of various pathogen species (Table 1) indicates that the strains carrying these particular mutations are sufficiently fit to survive and propagate in nature. Interestingly, the ability of $M$. graminicola to infect the host is not significantly reduced in SDH mutants despite a strong impairment in enzyme activity $(16,46)$. Also, B. cinerea and A. alternata-resistant and -sensitive field isolates possessed similar fitness characteristics and were able to infect host plants $(4,31,69)$. Further studies need to show whether fitness has a significant influence on the survival of SDHI-resistant strains in field populations and whether multiple resistance (e.g., to QoI) is altering the fitness characteristics.

Another important aspect to consider is that some of the SDHI fungicides are used exclusively as a seed treatment (sedaxane or penflufen) $(30,68)$ or as both foliar and seed treatments (fluxa- 
pyraxad and fluopyram $)(25,40)$. This needs to be considered in terms of selection of resistance in relation to the time of sowing, the activity at a particular point in time, and the epidemics of multiple pathogens on a given crop. The current discussion is about cereals, where sedaxane and fluxapyroxad will be launched shortly. The major discussion point is with regard to the activity of a specific fungicide applied as a seed treatment but also active against medium- to high-resistance-risk foliar pathogens; more specifically, whether the seed treatment should be counted from a resistance perspective as one of a total number of applications and, further, whether potential resistance modifiers (seed treatment mixtures, alternation, or dose rates) can be considered as valuable means to reduce selection pressure (17).

In conclusion, the SDHI fungicides constitute new, highly active tools to be used in sustainable and efficient disease control. As shown in this review, they are at risk of resistance development and need proper protection by suitable antiresistance management strategies. The early establishment of such recommendations by the industry and official and private advisors is expected to delay field resistance. However, due to the broad diversity of mutations observed, the final impact on field performance of SDHIs (solo or in mixture) needs to be further characterized so that it can be better understood.

Mutation numbering in the $s d h$ genes of different pathogens. Due to differences in length of the particular $s d h$ genes in different fungal plant pathogens, homolog positions do not necessarily have the same amino acid number when compared across different species: for example, the SDHB H267Y7L/R of M. graminicola is homologous to position 249 in A. oryzae, 257 in $U$. maydis, 272 in A. alternata and B. cinerea, and 277 in $D$. bryoniae and Pyrenophora teres. This is also the case for the other $s d h$ genes (e.g., SDHC H145R of M. graminicola is homologous to position 134 in A. alternaria). The position SDHB 267 and homologs is located at the bottom of the Qp site cavity, whereas the position SDHC 145 is involved in heme's iron chelation. The exact alignment of the different $s d h$ genes can be performed on a molecular resource platform, such as http:// www.ncbi.nlm.nih.gov/.

\section{LITERATURE CITED}

1. Alberoni, G., Ciriani, A., Banorri, M., Collina, M., and Brunelli, A. 2011. Sensitivity to Boscalid of Stemphylium vesicarium and Botrytis cinerea in Italy. Pages 273-277 in: Modern Fungicides and Antifungal Compounds, Vol. VI. H. W. Dehne, H. B. Deising, U. Gisi, K. H. Kuck, P. E. Russell, and H. Lyr, eds. DPG, Braunschweig, Germany.

2. Ammermann, E., Stierl, R., Hanke, W., Scherer, M., Ypema, H., and Bardinelli, T. 2002. Nicobifen*-the foundation of a new fungicide family. (Abstr.) Phytopathology 92(suppl.):S4.

3. Anonymous. 2012. SDHI fungicides: Should you use one? Farm. Week. 13:42.

4. Avenot, H. F., and Michailides, T. J. 2007. Resistance to boscalid fungicide in Alternaria alternata isolates from pistachio in California. Plant Dis. 91:1345-1350.

5. Avenot, H. F., and Michailides, T. J. 2009. Monitoring the sensitivity to boscalid of Alternaria alternata populations from California pistachio orchards. (Abstr.) Phytopathology 99:S6.

6. Avenot, H. F., and Michailides, T. J. 2010. Progress in understanding molecular mechanisms and evolution of resistance to succinate dehydrogenase inhibiting (SDHI) fungicides in phytopathogenic fungi. Crop Prot. 29:643-651.

7. Avenot H. F., Sellam, A., Karaoglanidis, G., and Michailides, T. J. 2008. Characterization of mutations in the iron-sulphur subunit of succinate dehydrogenase correlating with boscalid resistance in Alternaria alternata from California pistachio. Phytopathology 98:736-742.

8. Avenot, H. F., Thomas, A., Gitaitis, R. D., Langston, D. B., Jr., and Stevenson, K. L. 2012. Molecular characterization of boscalid- and penthiopyrad-resistant isolates of Didymella bryoniae and assessment of their sensitivity to fluopyram. Pest. Manage. Sci. 68:645-651.

9. Avenot, H. F., van der Biggelaar, H., Morgam, D. P., and Michailides, T. J. 2012. Fungicidial activity of fluopyram for suppression of Alternaria species pathogenic on California pistachio. Resist. Pest Manage. Newsl. 22:10-14.

10. Bardas, G. A., Veloukas, T., Koutita, O., and Karaoglanidisa, G. S. 2011. Multiple resistance of Botrytis cinerea from kiwifruit to SDHIs, QoIs and fungicides of other chemical groups. Pest Manage. Sci. 66:967-973.

11. Berdugo, C. A., Steiner, U., Oerke, E.-C., and Dehne, H.-W. 2011. Effects of the new SDHI fungicide bixafen on the physiology and yield of wheat plants. Pages 81-84 in: Modern Fungicides and Antifungal Compounds, Vol. VI. H. W. Dehne, H. B. Deising, U. Gisi, K. H. Kuck, P. E. Russell, and H. Lyr, eds. DPG, Braunschweig, Germany.

12. Broomfield, P. L. E., and Hargreaves, J. A. 1992. A single amino-acid change in the iron-sulphur protein subunit of succinate dehydrogenase confers resistance to carboxin in Ustilago maydis. Curr. Genet. 22:117121.

13. Cecchini, G. 2003. Function and structure of complex II of the respiratory chain. Annu. Rev. Biochem. 72:77-109.

14. Chen, W. J., Delmotte, F., Richard-Cervera, S., Douence, L., Greif C., and Corio-Costet, M. F. 2007. At least two origins of fungicide resistance in grapevine downy mildew populations. Appl. Environ. Microbiol. 73:51625172.

15. Fairchild, K. L., Miles, L. A., Miles, T. D., and Wharton, P. S. 2012. Detection and characterization of boscalid resistance in Alternaria solani causing early blight on potatoes in Idaho. Page 224 in: Proc. Am. Phytopathol. Soc. Annu. Meet. Rhode Island.

16. Fraaije, B. A., Bayon, C., Atkins, S., Cools, H. J., Lucas, J. A., and Fraaije, M. W. 2011. Risk assessment studies on succinate dehydrogenase inhibitors, the new weapon in the battle to control Septoria leaf blotch in wheat. Mol. Plant Pathol. 13:263-275.

17. FRAC (fungicide resistance action committee), Crop Life. www.frac.info

18. Georgopoulos, S. G., Alexandri, E., and Chrysayi, M. 1972. Genetic evidence for the action of oxathiin and thiazole derivatives on the succinic dehydrogenase system of Ustilago maydis mitochondria. J. Bacteriol. 110:809-817.

19. Georgopoulos, S. G., and Ziogas, B. N. 1977. A new class of carboxinresistant mutants of Ustilago maydis. Neth. J. Plant Pathol. 83 (Suppl. 1):235-242.

20. Glättli, A., Grote, T., and Stammler, G. 2011. SDH-inhibitors: History, biological performance and molecular mode of action. Pages 159-170 in: Modern Fungicides and Antifungal Compounds, Vol. VI. H. W. Dehne, H. B. Deising, U. Gisi, K. H. Kuck, P. E. Russell, and H. Lyr, eds. DPG, Braunschweig, Germany.

21. Glättli, A., Stammler, G., and Schlehuber, S. 2009. Mutations in the target proteins of succinatedehydrogenase inhibitors (SDHI) and $14 \alpha$-demethylase inhibitors (DMI) conferring changes in the sensitivity-structural insights from molecular modeling. Pages 670-681 in: 9th Int. Conf. Plant Dis. Tours, France.

22. Grouet, D., Montfort, F., and Leroux, P. 1981. Resistance to carboxin and fenfuram in Ustilago nuda (Jens.) Rostr., the causal agent of loose smut. Phytiatrie-Phytopharmacie 30:3-12.

23. Guirong, Z. 2012. Cercospora sojina: Over-winter survival and fungicide resistance. Ph.D. dissertation, University of Illinois, Urbana-Champaign.

24. Harp, T. L., Godwin, J. R., Scalliet, G., Walter, H., Stalker, A. D., Bartelett, D. W., and Ranner, D. J. 2011. Isopyrazam, a new generation cereal fungicide. Asp. Appl. Biol. 106:113-120.

25. Heger, M., Cavell, P., Wetjen, T., and Groeger, U. 2012. Systiva: A new concept for cereal disease control. Page 293 in: Proc. 58th German Plant Prot. Conf. Braunschweig, Quedlinburg, JKI, Berlin.

26. Huang, L. S., Sun, G., Cobessi, D., Wang, A. C., Shen, J. T., Tung, E. Y., Anderson, V. E., and Berry, E. A. 2006. 3-nitropropionic acid is a suicide inhibitor of mitochondrial respiration that, upon oxidation by complex II, forms a covalent adduct with a catalytic base arginine in the active site of the enzyme. J. Biol. Chem. 281:5965-5972.

27. Ishii, H., Miyamoto, T., Ushiod, S., and Kakishimab, M. 2010. Lack of cross-resistance to a novel succinate dehydrogenase inhibitor, fluopyram, in highly boscalid-resistant isolates of Corynespora cassiicola and Podosphaera xanthii. Pest. Manage. Sci. 67:474-482.

28. Ito, Y., Muraguchi, H., Seshime, Y., Oita, S., and Yanagi, S. O. 2004. Flutolanil and carboxin resistance in Coprinus cinereus conferred by a mutation in the cytochrome $b 560$ subunit of succinate dehydrogenase complex (complex II). Mol. Gen. Genomics 272:328-335.

29. Keon, J. P. R., White, G. A., and Hargreaves, J. A. 1991. Isolation, characterization and sequence of a gene conferring resistance to the systemic fungicide carboxin from the maize smut pathogen, Ustilago maydis. Curr. Genet. 19:475-481.

30. Kerz-Möhlendick, F. 2012. EmestoR: The new standard for protecting potato tubers. Page 293 in: Proc. 58th German Plant Prot. Conf. Braunschweig, Quedlinburg, JKI, Berlin.

31. Kim, Y. K., and Xiao, C. L., 2011. Stability and fitness of pyraclostrobinand boscalid-resistant phenotypes in field isolates of Botrytis cinerea 
from apple. Phytopathology 101:1385-1391.

32. Kleffmann amis (Agricultural Marketing Information System) 2012. Crop protection cereals-DE/Germany. http://www.ibr-ltd.com/services/marketdata/

33. Labourdette, G., Lachaise, H., Rieck, H., and Steiger, D. 2011. Fluopyram: Efficacy and beyond on problematic Diseases. Pages 75-80 in: Modern Fungicides and Antifungal Compounds, Vol. VI. H. W. Dehne, H. B. Deising, U. Gisi, K. H. Kuck, P. E. Russell, and H. Lyr, eds. DPG, Braunschweig, Germany.

34. Leroux, P., and Berthier, G. 1988. Mise en evidence, en France, d'une souche de Puccinia horiana résistante à l'oxycarboxine. Crop Prot. 7:1619.

35. Leroux, P., Gredt, M., Leroch, M., and Walker, A. S. 2010. Exploring mechanisms of resistance to respiratory inhibitors in field strains of Botrytis cinerea, the causal agent of gray mold. Appl. Environ. Microbiol. 76:6615-6630.

36. McGrath, M. T. 2008. Fungicide sensitivity in Podosphaera xanthii and efficacy for cucurbit powdery mildew in NY, USA, in 2003-2006. J. Plant Pathol. 90:90.

37. Menzies, J., McLeod, R., Tosi, L., and Cappelli, C. 2005. Occurrence of a carboxin-resistant strain of Ustilago nuda in Italy. Phytopathol. Mediterr. 44:216-219.

38. Miyamoto, T., Ishii, H., Seko, T., Kobori, S., and Tomita, Y. 2009. Occurrence of Corynespora cassiicola isolates resistant to boscalid on cucumber in Ibaraki Prefecture, J. Plant Pathol. 58:1144-1151.

39. Miyamoto, T., Ishii, H., and Tomita, Y. 2010. Occurrence of boscalid resistance in cucumber powdery mildew disease in Japan and the molecular characterization of iron-sulfur protein of succinate dehydrogenase of the causal fungus. J. Gen. Plant Pathol. 76:261-267.

40. Neubauer, K., 2012. EfA Universal-Ein neues Produkt zur Saatgutbehandlung von Getreide gegen Pilzkrankheiten. Pages 43-44 in: 53. Österreichische Pflanzenschutztage, Wels, Austria. www.oeaip.at

41. Newcombe, G., and Thomas, P. L. 1991. Incidence of carboxin resistance in Ustilago nuda. Phytopathology 81:247-250.

42. Newcombe, G., and Thomas, P. L. 2000. Inheritance of carboxin resistance in a European field isolate of Ustilago nuda. Phytopathology 90:179-182.

43. Olaya, G., Buitrago, C., Pearsaul, D., Sierotzki, H., and Tally, A. 2012. Detection of resistance to QoI fungicides in Rhizoctonia solani isolates from rice. Page 241 in: Proc. Am. Phytopathol. Soc. Annu. Meet. Rhode Island.

44. Rheinheimer, J. 2007. Succinate dehydrogenase inhibitors. Pages 496-505 in: Modern Crop Protection, Vol 2. W. Krämer and U. Schirmer, eds. Wiley-VCH, Weinheim, Germany.

45. Ruprecht, J., Yankovskaya, V., Maklashina, E., Iwata, S., and Cecchini, G. 2009. Structure of Escherichia coli succinate:quinone oxidoreductase with an occupied and empty quinone-binding site. J. Biol. Chem. 284:29836-29846.

46. Scalliet, G., Bowler, J., Luksch, T., Kirchhofer-Allan, L., Steinhauer, D., Ward, K., Niklaus, M., Verras, A., Csukai, M., Daina, A., and FonnéPfister, R. 2012. Mutagenesis and functional studies with succinate dehydrogenase inhibitors in the wheat pathogen Mycosphaerella graminicola. PLoS ONE 7:e35429. Online publication. doi:10.1371/journal. pone.0035429

47. Semar, M., Strobel, D., Strathmann, S., and Groeger, U. 2011. Xemiumthe BASF fungicide innovation. Pages 63-68 in: Modern Fungicides and Antifungal Compounds, Vol. VI. H. W. Dehne, H. B. Deising, U. Gisi, K. H. Kuck, P. E. Russell, and H. Lyr, eds. DPG, Braunschweig, Germany.

48. Shima, Y., Ito, Y., Kaneko, S., Hatabayashi, H., Watanabe, Y., Adachi, Y., and Yabe, K. 2009. Identification of three mutant loci conferring carboxin-resistance and development of a novel transformation system in Aspergillus oryzae. Fungal Genet. Biol. 46:67-76.

49. Sierotzki, H., Frey, R., Morchoisne, M., Olaya, G., Mösch, M., and Scalliet, G. 2011. Sensitivity of fungal pathogens to SDHI fungicides. Pages 179-186 in: Modern Fungicides and Antifungal Compounds, Vol. VI. H. W. Dehne, H. B. Deising, U. Gisi, K. H. Kuck, P. E. Russell, and H. Lyr, eds. DPG, Braunschweig, Germany.

50. Silkin, Y., Oyedotun, K. S., and Lemire, B. D. 2007. The role of Sdh4p Tyr-89 in ubiquinone reduction by the Saccharomyces cerevisiae succinate dehydrogenase. Biochim. Biophys. Acta 1767:143-150.

51. Skinner, W., Bailey, A., Renwick, A., Keon, J., Gurr, S., and Hargreaves,
J. 1998. A single amino acid substitution in the iron sulphur protein of succinate dehydrogenase determines resistance to carboxin in Мycosphaerella graminicola. Curr. Genet. 34:393-398.

52. Stammler, G., Brix, H.-D., Glaettli, A., Semar, M., and Schoefl, U. 2007. Biological properties of the carboxamide boscalid including recent studies on its mode of action. Pages 16-21 in: Proc. 16th Int. Congr. Plant Prot. Session 2A, Glasgow, UK

53. Stammler, G., Glättli, A., Koch, A., and Schlehuber, S. 2011. Mutations in the target protein conferring resistance to SDHI fungicides. Pages 195198 in: Modern Fungicides and Antifungal Compounds, Vol. VI. H. W. Dehne, H. B. Deising, U. Gisi, K. H. Kuck, P. E. Russell, and H. Lyr, eds. DPG, Braunschweig, Germany.

54. Stevenson, K. L., Langston, D. B., Jr., and Sanders, F. 2008. Baseline sensitivity and evidence of resistance to boscalid in Didymella bryoniae. (Abstr.) Phytopathology 98:S151.

55. Sun, F., Huo, X., Zhai, Y., Wang, A., Xu, J., Su, D., Bartlam, M., and Rao, Z. 2005. Crystal structure of mitochondrial respiratory membrane protein complex II. Cell 121:1043-1057.

56. Suty-Heinze, A., Dunkel, R., Krieg, U., and Rieck, H. 2011. Bixafen-the new cereal fungicide with yield boosting effects. Pages 69-74 in: Modern Fungicides and Antifungal Compounds, Vol. VI. H. W. Dehne, H. B. Deising, U. Gisi, K. H. Kuck, P. E. Russell, and H. Lyr, eds. DPG, Braunschweig, Germany.

57. Torriani, S. F. F., Brunner, P. C., McDonald, B. A., and Sierotzki, H. 2009. QoI resistance emerged independently at least 4 times in European populations of Mycosphaerella graminicola. Plant Pathol. 65:155-162.

58. Tran, Q. M., Rothery, R. A., Maklashina, E., Cecchini, G., and Weiner, J. H. 2006. The quinone binding site in Escherichia coli succinate dehydrogenase is required for electron transfer to the heme b. J. Biol. Chem. 281:32310-32317.

59. Van Tuyl, J. M. 1975. Acquired resistance to carboxin in Aspergillus nidulans. Neth. J. Plant Pathol. 81:122-123.

60. Veloukas, T., Anastasios, N,. Markoglou, A. N., and Karaoglanidis, G. S. 2012. Differential effect of $S d h B$ gene mutations on the sensitivity to SDHI fungicides in Botrytis cinerea. Plant Dis. 97:118-122.

61. Von Schmeling, B., and Kulka, M. 1966. Systemic fungicidal activity of 1,4-oxathiin derivates. Science 152:659-660.

62. Walker, A.-S., Gredt, M., and Leroux, P. 2011. Resistance to QoIs and SDHIs in populations of Botrytis cinerea. Pages 187-194 in: Modern Fungicides and Antifungal Compounds, Vol. VI. H. W. Dehne, H. B. Deising, U. Gisi, K. H. Kuck, P. E. Russell, and H. Lyr, eds. DPG, Braunschweig, Germany.

63. Walter, H. 2011. New fungicides and new modes of action. Pages 47-54 in: Modern Fungicides and Antifungal Compounds, Vol. VI. H. W. Dehne, H. B. Deising, U. Gisi, K. H. Kuck, P. E. Russell, and H. Lyr, eds. DPG, Braunschweig, Germany.

64. White, G. A., and Thorn, G. D. 1980. Thiophene carboxamide fungicides: Structure-activity relationships with the succinate dehydrogenase complex from wild-type and carboxin-resistant mutant strains of Ustilago maydis. Pest. Biochem. Physiol. 14:26-40.

65. Yanase, Y., Yoshikawa, Y., Kishi, J., and Katsuta, H. 2007. The history of complex II inhibitors and the discovery of penthiopyrad. Pages 295-303 in: Pesticide Chemistry. Crop Protection, Public Health, Environmental Safety. H. Ohkawa, H. Miyagawa, and P. W. Lee, eds. Wiley-VCH Verlag $\mathrm{GmbH} \&$ Co. KGaA, Weinheim, Germany.

66. Yankovskaya, V., Horsefield, R., Tornroth, S., Luna-Chavez, C., Miyoshi, H., Léger, C., Byrne, B., Cecchini, G., and Iwata, S. 2003. Architecture of succinate dehydrogenase and reactive oxygen species generation. Science 299:700-704.

67. Yin, Y. N., Kim, Y. K., and Xiao, C. L. 2011. Molecular characterization of boscalid resistance in field isolates of Botrytis cinerea from apple. Phytopathology 101:986-995.

68. Zeun, R., Scalliet, G., and Oostendorp, M. 2012. Biological activity of sedaxane- a novel broad-spectrum fungicide for seed treatment. Pest Manage. Sci. Online publication. doi:10.1002/ps.3405.

69. Zhang, C. Q., Yuan, S. K., Sun, H. Y., Zhou, M. G., and Zhu, G. N. 2007. Sensitivity of Botrytis cinerea from vegetable greenhouses to boscalid. Plant Pathol. 56:646-653.

70. Zhou, Q. J., Zhai, Y. J., Liu, M., and Sun, F. 2011. Thiabendazole inhibits ubiquinone reduction activity of mitochondrial respiratory complex II via a water molecule mediated binding feature. Prot. Cell 2:531-542. 